\title{
Behavioral Conceptualization and Treatment of Chronic Pain
}

Citation for published version (APA):

Vlaeyen, J. W. S., Crombez, G., Widiger, T., \& Cannon, T. D. (2020). Behavioral Conceptualization and Treatment of Chronic Pain. Annual Review of Clinical Psychology, 16, 187-212. https://doi.org/10.1146/annurev-clinpsy-050718-095744

Document status and date:

Published: 01/01/2020

DOI:

10.1146/annurev-clinpsy-050718-095744

Document Version:

Publisher's PDF, also known as Version of record

Document license:

Taverne

Please check the document version of this publication:

- A submitted manuscript is the version of the article upon submission and before peer-review. There can be important differences between the submitted version and the official published version of record.

People interested in the research are advised to contact the author for the final version of the publication, or visit the DOI to the publisher's website.

- The final author version and the galley proof are versions of the publication after peer review.

- The final published version features the final layout of the paper including the volume, issue and page numbers.

Link to publication

\footnotetext{
General rights rights.

- You may freely distribute the URL identifying the publication in the public portal. please follow below link for the End User Agreement:

www.umlib.nl/taverne-license

Take down policy

If you believe that this document breaches copyright please contact us at:

repository@maastrichtuniversity.nl

providing details and we will investigate your claim.
}

Copyright and moral rights for the publications made accessible in the public portal are retained by the authors and/or other copyright owners and it is a condition of accessing publications that users recognise and abide by the legal requirements associated with these

- Users may download and print one copy of any publication from the public portal for the purpose of private study or research.

- You may not further distribute the material or use it for any profit-making activity or commercial gain

If the publication is distributed under the terms of Article $25 \mathrm{fa}$ of the Dutch Copyright Act, indicated by the "Taverne" license above, 


\title{
'R REVIEWS
}

\section{Annual Review of Clinical Psychology \\ Behavioral Conceptualization and Treatment of Chronic Pain}

\author{
Johan W.S. Vlaeyen ${ }^{1,2}$ and Geert Crombez ${ }^{3,4}$ \\ ${ }^{1}$ Research Group on Health Psychology, Faculty of Psychology and Educational Sciences, \\ University of Leuven, 3000 Leuven, Belgium; email: johannes.vlaeyen@kuleuven.be \\ ${ }^{2}$ Experimental Health Psychology, Maastricht University, 6211 LK Maastricht, The Netherlands \\ ${ }^{3}$ Department of Experimental-Clinical and Health Psychology, Faculty of Psychology and \\ Educational Sciences, Ghent University, 9000 Ghent, Belgium \\ ${ }^{4}$ Centre for Pain Research, University of Bath, Bath BA2 7AY, United Kingdom
}

Annu. Rev. Clin. Psychol. 2020. 16:187-212

First published as a Review in Advance on December 10, 2019

The Annual Review of Clinical Psychology is online at clinpsy.annualreviews.org

https://doi.org/10.1146/annurev-clinpsy-050718095744

Copyright (ㄷ 2020 by Annual Reviews.

All rights reserved

\section{timum CONNECT}

www.annualreviews.org

- Download figures

- Navigate cited references

- Keyword search

- Explore related articles

- Share via email or social media

\section{Keywords}

chronic pain, behavior, motivation, learning, conditioning, fear avoidance

\begin{abstract}
Pain is considered a hardwired signal of bodily disturbance belonging to a basic motivational system that urges the individual to act and to restore the body's integrity, rather than just a sensory and emotional experience. Given its eminent survival value, pain is a strong motivator for learning. Response to repeated pain increases when harm risks are high (sensitization) and decreases in the absence of such risks (habituation). Discovering relations between pain and other events provides the possibility to predict (Pavlovian conditioning) and control (operant conditioning) harmful events. Avoidance is adaptive in the short term but paradoxically may have detrimental longterm effects. Pain and pain-related responses compete with other demands in the environment. Exposure-based treatments share the aim of facilitating or restoring the pursuit of individual valued life goals in the face of persistent pain, and further improvements in pain treatment may require a paradigm shift toward more personalized approaches.
\end{abstract}




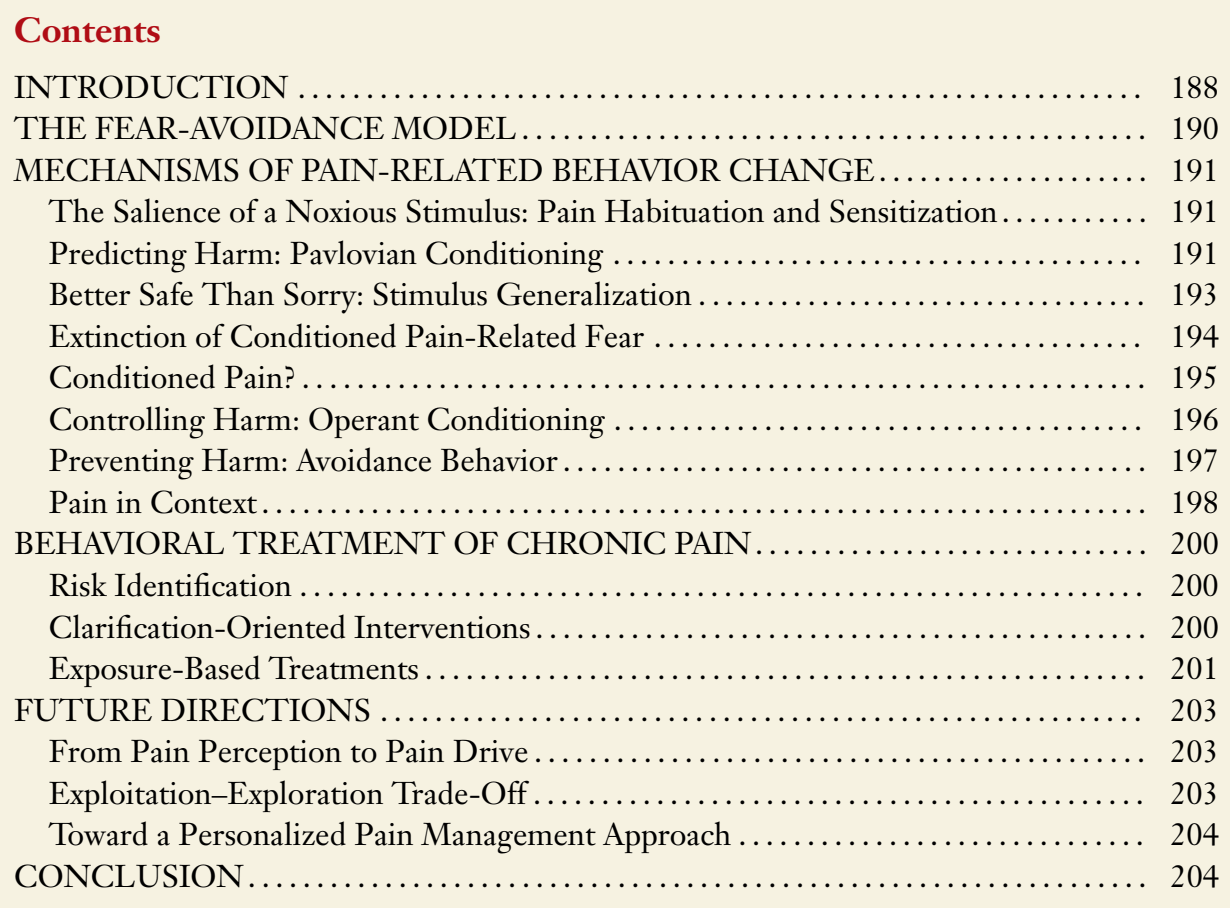

\section{INTRODUCTION}

Acute pain is a normal part of life, and most often it resolves quickly within a few weeks. There are instances, however, in which pain returns intermittently or remains for longer periods of time. Chronic pain, defined as pain persisting longer than 3 months, is one of the most prevalent and costly sources of human suffering, especially in (but not limited to) modern industrialized societies. In children and adolescents, the estimated median prevalence of chronic and recurrent pain is $23 \%$ for headache and ranges from $11 \%$ to $38 \%$ for other types of pain (i.e., abdominal pain, back pain, musculoskeletal pain, and pain combinations) (King et al. 2011). Girls generally experience more pain than boys, and prevalence rates increase with age. Strikingly, prevalence rates of pain in youth have increased over the last decades. In adults, the median prevalence of chronic low back pain lies between 5.6\% and 18.1\% (Henschke et al. 2015). For 2012, 126.1 million US adults reported some pain in the previous 3 months, of whom $11.2 \%$ reported suffering from daily pain, and $10.3 \%$ reported severe pain (Nahin 2015). The burden of chronic pain is unquestionably large, both in youth and in adults. The 2010 Global Burden of Disease Study and its subsequent reports revealed that various forms of pain such as low back pain, headache, and neck pain impose the highest disability burden of all specific conditions, with low back pain contributing the highest number of years lived with disability (Buchbinder et al. 2013). The costs of chronic pain have been estimated to exceed the combined costs of heart disease, cancer, and diabetes (Gaskin \& Richard 2012).

Traditionally, pain is considered a direct sign of underlying injury, tissue damage, or organic pathology. Its reported intensity is thought to be consistent with the extent of bodily harm inflicted. Such a Cartesian view of pain has been influential for a long time. Clinicians often use pain as an index for the location and physiological properties of the injury (Gray 2019), and laypeople 
commonly adhere to a biomedical orientation considering pain as an unambiguous signal of tissue damage that inevitably leads to disability such as work loss (De Ruddere et al. 2012). These erroneous beliefs have also been coined "myths about pain" (Malec et al. 1977). Indeed, numerous studies illustrate that the report of pain, either acute or chronic, is not strongly correlated with the presence of tissue damage. For example, abnormal findings on magnetic resonance imaging of the lumbar spine, such as bulged disks or protrusions, are found in asymptomatic and uninjured adults as well, suggesting that medical findings are not necessarily causally related to the pain experienced (Brinjikji et al. 2015).

Pain and attempts to alleviate it have always been part of human experience, and yet a complete grasp of its causes, functions, and consequences has proven elusive. Despite the technological advancements of the last decade, the neurological signature of pain and the transition from acute to chronic pain are still unclear (Mouraux \& Iannetti 2018). Biological theories, even very sophisticated ones, have failed to account for individual differences in pain behaviors and the propensity to develop chronic pain. One likely reason is that pain is an idiosyncratic experience that cannot be shared with others. In addition, the extant literature on brain imaging in chronic back pain suggests that the neural signature more closely resembles that of emotion processing than that of acute pain (Hashmi et al. 2013).

The definition of pain by the International Association for the Study of Pain (IASP) recognizes the loose connection between tissue damage and the report of pain: "Pain is an unpleasant sensory and emotional experience associated with actual or potential tissue damage, or described in terms of such damage" (IASP 1979). The definition represents a radical rupture with the traditional biomedical model of pain and calls on clinicians to take patients seriously when they report pain, even in the absence of tissue damage. Ever since, self-report has globally become the gold standard for assessment of pain by clinicians and scientists alike.

The IASP definition does not address the impact of pain on daily functioning. It is commonly believed that pain always has a detrimental impact on daily life. This is not necessarily the case, and pain does not inevitably lead to disability. On the one hand, a relatively large subgroup of individuals report chronic pain that does not interfere with their daily life; depending on the broadness of the definition of pain used, this subgroup ranges from $5 \%$ to $28 \%$ of all people reporting chronic pain (Jordan et al. 2019). On the other hand, roughly $5 \%$ report pain with high impact on daily functioning. This group is more likely than persons with chronic pain without disability to report mental health problems, cognitive complaints, difficulty with self-care, and greater health care use (Pitcher et al. 2019). In summary, pain cannot be equated with disability.

What perhaps are most missing in the well-accepted definition of pain are the behavioral and motivational effects of pain. Typically, pain urges a person to act, and it interrupts ongoing activities. These characteristics may not be unique to pain, but they are nevertheless foundational to its experience. A life without pain is dangerous; children with congenital insensitivity to pain experience unnoticed bruises, cuts, and burns and are at high risk of early death (Cox et al. 2006). Already in 1897, Charles Darwin, when studying expressions of emotion in humans and animals, observed, "Great pain urges all animals...to make the most violent and diversified efforts to escape from the cause of suffering" (Darwin 1897, p. 72). This idea was further elaborated on by Eccleston \& Crombez (1999, p. 356), who argued that "pain is selected for action from within complex affective and motivational environments to urge escape." Pain is thus akin to hunger and thirst, which are homeostatic motivations that maintain an optimal balance in the physiological condition of the body for the purpose of survival (Auvray et al. 2010, Craig 2002, Wall 1979).

This review proceeds from the position that pain is not only a sensory and emotional experience but also part of a motivational system that alarms, directs, and energizes behavior to minimize bodily harm. To defend the integrity of the body in a natural environment, the 
organism continuously adapts its behavioral repertoire, guided by predictions of the potential occurrence of harmful stimuli and by the outcomes of behavioral attempts to protect against these stimuli. From this perspective, pain is a strong driver of learning. A cognitive behavioral theoretical model that fits this position quite well is the fear-avoidance (FA) model of chronic pain, which presents a plausible pathway by which individuals can get caught in a downward negative spiral starting from catastrophic misinterpretations of pain toward disability. We describe the underlying learning mechanisms and highlight mechanisms of pain-related behavior change by which initially adaptive learning turns into a less flexible pattern of behavior, which perpetuates pain and pain-related problems. We include habituation and sensitization, learning to predict and control harmful events, and the putative role of these processes in the maintenance of chronic pain problems. These forms of learning do not occur in a vacuum. In natural settings, learning and resulting behavior change emerge in a context of other, often-competing demands or needs. Understanding chronic pain behavior thus requires the context in which these behaviors emerge. Finally, we review existing behavioral treatments that help individuals restore or adjust their behavioral repertoire, promote resilience, and enable them to reprioritize toward valued life goals.

\section{THE FEAR-AVOIDANCE MODEL}

The somewhat provocative statement "Fear of pain and what we do about it may be more disabling than pain itself" (Waddell et al. 1993, p. 164) nicely captures a shift away from pain severity as the direct cause of difficulties in performing daily life activities. The acknowledgment of a close relationship between fear and pain is not new. Aristotle wrote, "Let fear be a pain or disturbance on account of an appearance of future evil which is destructive or painful" (Fortenbaugh 1969, p. 166). Pain drives action by virtue of its emotional dimension. Fear is known to promote defensive (avoidance) behaviors that diminish anticipated danger in the short term. Depression is typically associated with social withdrawal and reduced physical activity. More recently, a number of theoretical building blocks have been identified, resulting in what is currently known as the FA model of pain. It combines cognitive, emotional, motivational, and behavioral aspects of pain-related behavior into an integrated theoretical framework. Lethem and colleagues (1983) were the first to coin the term "fear-avoidance" model; they postulated two behavioral responses to fear of pain, of which avoidance leads to the maintenance of pain over time. A similar account was presented by Steven Linton, whose "activity-avoidance" model of chronic pain predicts that it is persistent avoidance of activities after normal healing time that ultimately leads to disability (Linton et al. 1984). More cognitively oriented accounts introduced later suggest that avoidance behavior can be a consequence of (mis)interpretations of pain as a sign of serious harm (Philips 1987, Vlaeyen et al. 1995).

In contrast to other psychological approaches, the FA model is relatively specific, and it primarily applies to the subgroup of patients who express fears that engaging in painful movements or activities will result in further bodily harm or (re)injury. The model proposes that fear-related defensive behaviors spiral into a vicious and self-perpetuating cycle that promotes activity limitations, disability, negative affect, and pain. A relatively large body of evidence is in line with this model's assumptions; this evidence stems from cross-sectional studies of chronic pain (Zale et al. 2013), prospective studies of acute pain (Gheldof et al. 2007), and studies using structural equation modeling examining the dynamic and sequential relationships among the variables of the FA model (Gheldof et al. 2010, Wideman et al. 2009). A systematic review and meta-analysis concluded that despite the low quality of the investigations, pain-related fear is associated with chronic musculoskeletal pain and disability and is a precursor to chronic pain and disability (MartinezCalderon et al. 2019). Since its conception almost 40 years ago, the FA model has influenced 
clinicians' perceptions of chronic pain, exerted an applied impact on pain management, stimulated research in pain science, and generated consilience across diverse domains of knowledge outside the pain field, including fatigue in multiple sclerosis (Bol et al. 2010), cardiovascular disease (Brunetti et al. 2017), falling in the elderly (Delbaere et al. 2009), and traumatic brain injury (Wijenberg et al. 2017). Despite these strengths, the FA model is still a theory-based heuristic in search of a better understanding of the dynamics of pain and pain disability and is continuously being adjusted and refined (Crombez et al. 2012, Wideman et al. 2013). In the remainder of this review, we provide an update on the learning mechanisms behind pain-related behavior in the context of pain and competing demands, and we highlight the clinical implications.

\section{MECHANISMS OF PAIN-RELATED BEHAVIOR CHANGE}

\section{The Salience of a Noxious Stimulus: Pain Habituation and Sensitization}

One of the most elementary forms of learning can be observed after repeated encounters with a single painful stimulus. A decrease in the strength of responding to a single stimulus because of repeated exposures is habituation, whereas an increase is sensitization. Habituation and sensitization are two basic but nontrivial phenomena observed in many species (including some unicellular organisms), across various response modalities, and in response to a broad range of stimuli (Rankin et al.2009). The observation that habituation and sensitization are evolutionarily conserved so well indicates that they confer a strong behavioral advantage. Habituation can be considered learning to not respond to stimuli that do not provide salient information, whereas sensitization is learning to respond to stimuli that might threaten the integrity of the organism and compromise survival (Latremoliere \& Woolf 2009).

Although habituation and sensitization both have been extensively studied for many years, it is intriguing that the repetition of a noxious stimulus does not necessarily induce sensitization. Early theorists posited that habituation to painful heat stimuli was possible with extensive experience but that it was fragile and easy to disrupt (Hardy et al. 1952). Subsequent researchers on habituation suggested that habituation would exclusively occur with weak stimuli. However, in his groundbreaking theory on habituation, Evgeny Nikolaevich Sokolov (1963) proposed that the typical response to repeated stimuli would depend on whether the "orienting" system or the "defensive" system was activated. High-intensity stimuli, such as painful ones, would activate the defensive system, and their repetition would consequently lead to sensitization. A recent motivationalethological account of habituation argues that habituation to pain is best understood as the result of identifying particular painful events as false alarms-experiences that require no immediate or further action (De Paepe et al. 2019). Given that missing true alarms could come with huge costs, such mechanisms should be fine-tuned and are likely to be highly context- or stimulus-specific. From this perspective, habituation in one context does not necessarily generalize to other contexts, certain contexts (e.g., stressful events) might prevent habituation, and dishabituation is expected to occur when the threat value of the stimulus increases.

Reduced ability to habituate and increased sensitization are both thought to play a role in the development and maintenance of pain problems (Stankewitz \& May 2009, Woolf 2011). There is evidence that certain chronic pain syndromes may be characterized by reduced or more easily disrupted habituation, such as fibromyalgia (Smith et al. 2008), chronic low back pain (Vossen et al. 2015), and irritable bowel syndrome (Lowen et al. 2015), but the research is relatively scarce so far.

\section{Predicting Harm: Pavlovian Conditioning}

Given pain's alarming nature, the prediction of pain is critical to minimize the chance of bodily harm. Prediction can be realized by the detection of cues that precede or coincide with the 
occurrence of pain. This is the hallmark of Pavlovian conditioning. Its core elements are well known. A relatively neutral stimulus [the conditioned stimulus (CS)] that regularly precedes a biologically salient stimulus [the unconditioned stimulus (US)] will result in a behavior change toward the CS. Behaviors that were initially observed in response to the US [unconditioned response (UR)] can now (to some extent) be observed in response to the CS [conditioned response (CR)]. The strength of the UR may vary, and individuals who report pain to be highly threatening also show stronger unconditioned pain responses (Crombez et al. 1998a). Through repeated CS-US pairings, the meaning of the CS changes from a neutral event that can easily be dismissed to a salient cue with behavioral and motivational significance. Innate and hardwired behavioral responses to biologically significant events, such as pain, are swiftly learned in anticipation of these events, enabling an effective preparation for and efficient response to these events in their natural environment (Hollis 1984).

Pavlovian conditioning is one of the oldest and most studied learning processes in psychology, yet its specific application in pain research is more recent. In principle, any CS that precedes or concurs with a painful stimulus, whether exteroceptive (tactile, visual, auditory), interoceptive (visceral, olfactory), or kinesthetic/proprioceptive (change of position), can acquire motivational properties through the association with the painful stimulus (Cammer 1961). However, and probably for practical reasons, most experimental studies employ exteroceptive (mostly visual) CSs and include pain-related psychophysiological reactivity and fear responses as the CRs. For example, in one study, the color of a visual stimulus signaled the occurrence (CS+) or nonoccurrence (CS-) of a visceral painful stimulus (rectal distention). After acquisition, participants showed greater neural responses on a low-intensity US in the presence of the CS+ compared with CS- (Icenhour et al. 2017). Other studies have used somatosensory stimuli as CSs to better mimic the natural dynamics of learning pain-related fear in chronic pain. For example, as an analog to the fear of touch reported by patients with complex regional pain syndrome, a chronic pain syndrome characterized by allodynia (pain due to a stimulus that does not normally provoke pain), tactile stimuli on a finger were shown to elicit fear of painful touch after a differential Pavlovian conditioning procedure (Biggs et al. 2017).

Remarkably, most studies have investigated temporal contingencies between the CS and US, whereas spatiotemporal contingencies between the CS and the US may lead to different types of knowledge about the relation between the CS and US (Testa 1974). A CS may be perceived not merely as predicting the US but also as causing or producing the US, just like a syringe approaching one's arm will eventually produce pain. In that context, the Belgian learning psychologist Paul Eelen (2018) argued that Pavlovian conditioning is probably better framed as detecting and understanding regularities between events in the world by making inferences and attributions. Several experimental paradigms have been developed that allow investigation of the role of spatiotemporal contingency. For example, in one study, the hand of an experimenter approached the hand of a participant with a pen, and the color of the pen was the CS for producing a somatosensory stimulus at the same location (Van der Biest et al.2016). Other researchers have used active movements as the CS; the participant moved the arm, and the direction of the movement produced pain in the hand (Meulders et al. 2011). This new type of study may better mimic the knowledge structure of patients with chronic pain. For example, for patients with chronic low back pain, back-stressing movements are not merely experienced as predicting pain but, rather, as producing pain.

In various models explaining the transition from acute pain to chronic disabling pain, painrelated fear has a prominent role (Crombez et al. 1999, Lethem et al. 1983, Vlaeyen 2015, Vlaeyen \& Linton 2000). In an attempt to investigate the learning processes underlying fear of pain, Meulders et al. (2011) created the voluntary joystick movement paradigm (VJP) as an experimental analog for what might occur in individuals with chronic musculoskeletal pain. Joystick movements 
were proprioceptive CSs, the direction of which predicted painful stimuli to the hand (US). For example, moving upward was the $\mathrm{CS}+$, and moving downward was the CS-. Compared with a condition in which both movements were explicitly unpaired with the pain-US, the CS+ movement elicited increased fear of movement-related pain, larger eye-blink startle amplitudes, and slower movement latency responses than did the CS- (Meulders et al. 2011). The mere intention to perform a painful movement was associated with similar CRs (Meulders \& Vlaeyen 2013). For visceral pain, mild and strong esophageal or rectal balloon distensions have been used to mimic gastrointestinal symptoms (Ceunen et al. 2016, Icenhour et al. 2017), and tactile stimuli have been used to mimic allodynia in individuals with neuropathic pain (Biggs et al. 2017). Collectively, these studies clearly demonstrate that fear of pain can easily be acquired via Pavlovian conditioning.

At least three distinct pathways for acquiring knowledge between potential cues and pain have been proposed. First, humans learn by direct experience the relationship between cues and pain, as was the case in the abovementioned studies. However, there are also indirect pathways, such as transmission through verbal instruction and observational information. For the verbal pathway, there is abundant research showing that simply instructing participants about the relationship between the CS and the US is sufficient to instill "conditioned" fear, as measured via self-report and psychophysiology. For example, just verbally informing participants that a low-intensity electrocutaneous stimulus directly activates the pain fibers increases its motivational saliency (Crombez et al. 1998b). As yet, no substantial differences have been found between fear conditioning via verbal instructions and via direct experience (Mertens et al. 2018). The role of verbal information provided by peers, family, and health care practitioners may substantially influence fear learning in patients. It is well known that erroneous beliefs about pain are prevalent in laypersons (Goubert et al. 2004), but they also are found among health professionals (Caneiro et al. 2019, Houben et al. 2005). The use of medical terminology and certain expressions implying harm (e.g., "Your spine looks like one of a 70-year-old") may inadvertently evoke pain-related fear.

There is also a nonverbal pathway by which merely observing another person in pain can be sufficient to instill fear of that particular stimulus (Goubert et al. 2011). In one study, participants observed video clips showing human models who immersed their hand in two different cold-water tanks. The water of each tank had a different color (orange or pink), and the colors were associated with either painful or neutral facial expressions (Helsen et al. 2011). When tested after watching the video but before having their own hands immersed in these cold pressor tasks, the observers' fear and pain expectancy scores showed that they had learned the color CS-pain associations they previously had observed in the model. During the actual immersion after the observation, they still remained more fearful of the CS+ cold water task despite equal water temperatures in both tanks $\left(10^{\circ} \mathrm{C}\right)$. An intriguing yet untested idea is that interactions among these pathways may facilitate learning, which might be relevant in an interpersonal context (Vervoort \& Trost 2017). For example, previous observational learning may enhance subsequent experiential learning of pain-related fear during the actual encounter of a similar pairing between a CS and a painful stimulus.

\section{Better Safe Than Sorry: Stimulus Generalization}

In natural environments, salient stimuli exist in many shades and forms. Fortunately, individuals use perceptual proximity between CSs to extrapolate knowledge from one situation to other situations without actually having to experience them. Stimulus generalization reduces the risk of missing positive alarms (better safe than sorry) but carries the cost of an increased waste of energy in responding to false alarms. In the context of chronic pain, the spreading of defensive behavior over numerous events in the absence of any danger will increase interference with daily life activities and add to the level of disability and distress (Meulders et al. 2015). 
Using the VJP in healthy subjects, we were able to demonstrate a typical generalization gradient in eye-blink startle reflexes for novel movements that varied in similarity with the painful CS+ movement (Meulders \& Vlaeyen 2013). When the same task was conducted in patients with fibromyalgia (a chronic pain syndrome characterized by widespread pain), all novel stimuli appeared to elicit strong conditioned fear responses regardless of their perceptual resemblance to the original CS+ or CS-, and the extinction of the responses to the generalized stimuli was slower than in healthy controls (Meulders et al. 2015, 2017). In other words, it is perhaps not so much the intensity of the fear of pain response that contributes to disability but, rather, the (increasing) range of stimuli capable of predicting harm. However, more experimental and longitudinal studies in individuals with chronic pain are needed to draw definitive conclusions about the causal status of this particular transfer of learning.

Generalization through physical similarity of stimuli is a process that may help explain why patients are fearful of novel movements that were never experienced as painful. However, these events do not necessarily need to be physically similar to the CS. Conceptual sameness shared between events might also contribute to the generalization of learned fear, which is referred to as category-based or symbolic generalization (Dunsmoor \& Murphy 2015). In the context of musculoskeletal pain, it is conceivable that proprioceptive stimuli can evoke fear based on their membership in verbal categories. For example, a well-intending physiotherapist may advise, "Be cautious while lifting because it could damage your spine." Here, the verbal category label "lifting" may become conceptually related to the pain-relevant threat attribute "damage." As a result, other members of that category label "lifting" may also be associated with the same threat and elicit similar fear responses. Again using the VJP, Bennett et al. (2015) tested the hypothesis that pain-related fear can emerge as a result of such symbolic generalization. Using a matching-to-sample task, two artificial categories were established in which certain nonsense words and certain arm movements were learned as being equivalent. Then, nonsense words from one category were paired with an electrocutaneous stimulus (pain-US), whereas nonsense words from the other category were paired with a no-pain-US. The results showed that in a final testing phase, movements that were never followed by a painful US but were learned to be equivalent to the pain-relevant nonsense words evoked heightened fear of movement-related pain and pain expectancy. In the same vein, there is some evidence that conditioning can occur with symbolic representations of the pain-US rather than with its actual presentation (Jepma \& Wager 2015).

\section{Extinction of Conditioned Pain-Related Fear}

When the US ceases to follow the CS, the latter loses its predictive value, and consequently the CR is extinguished (Benson et al. 2014, Meulders \& Vlaeyen 2012). However, extinction is a fragile process because the original CS-US propositional knowledge remains stored in memory even after gathering disconfirmatory evidence. Extinction is also context dependent, and CRs may return when the individual encounters a novel CS that is slightly different from the extinguished CS. In one study, individuals with chronic low back pain were requested to perform each of two back-stressing movements twice (bending forward while standing and lifting one leg while lying down). The participants initially overpredicted the pain during a movement but readily corrected their prediction when the same movement was repeated (Crombez et al. 2002). However, in participants reporting catastrophic thoughts about pain, this exposure effect did not generalize to the second dissimilar movement, and the overprediction of pain reappeared. It looks like there is a clear asymmetry between swift generalization of the acquisition of pain-related fear and restricted generalization of the extinction of it (but see also Trost et al. 2008). The fragility of extinction is also evidenced by renewal and reinstatement effects. Renewal is the return of the CR when 
the extinguished CS is encountered in a different context from the one where extinction took place (Icenhour et al. 2015). Reinstatement is the return of the CR after an unexpected flare-up of pain-US or a nonpain stressor US (cross-reinstatement) (Gramsch et al. 2014). Reinstatement is particularly relevant for patients with chronic pain, who will occasionally experience pain exacerbations even after successful treatment.

\section{Conditioned Pain?}

As yet, we have discussed the literature of Pavlovian conditioning as a way to understand how and when patients with chronic pain may acquire pain-related fear. Acquired pain-related fear has been central in many models explaining chronic pain problems. However, Pavlovian conditioning has also provided other explanatory models of chronic pain. Here, we briefly elaborate on two of these ideas.

First, classical conditioning has been thought to be the underlying mechanism for the increased muscular reactivity often seen in chronic pain patients, which is assumed to prolong the symptoms and indirectly influence chronic pain (Flor \& Turk 1989, Schneider et al. 2004, Vlaeyen et al. 1999). Persistent muscle tone can eventually lead to ischemia and associated nociception. Using a differential conditioning paradigm with auditory CSs, Klinger et al. (2010) found that patients with chronic back pain and tension-type headache showed URs to an intracutaneous nociceptive stimulus in lumbar and trapezius muscles significantly more often than did healthy controls. The number of substantial electromyographic responses to the CS+ (a visual cue) was significantly higher than the number of responses to the CS-. Furthermore, a significant relation was found between conditioned muscular responses and the self-reported pain intensity 1 day after the experiment. Chronic low back pain patients with high levels of pain-related fear were characterized by a higher skin conductance response, heart rate acceleration, and increased lower back muscle tension compared with patients with lower levels of pain-related fear when they were exposed to images of back-stressing activities with the instruction to perform these movements later on (Glombiewski et al. 2015).

The second idea is intriguing but still controversial. It concerns the question of whether pain itself can be the direct result of Pavlovian conditioning. One of the first empirical examples of experimentally conditioned sensations was provided by Carl Emil Seashore (1895), who was interested in perceptual distortions in the everyday life of healthy individuals. Seashore undertook various experiments to test whether manipulating people's expectations influenced their perceptions, including those of light, taste, warmth, and electric stimuli. He followed a standard procedure in which he first established the sensory threshold, followed by a number of repeated exposures to the physical stimulus, terminating with an experimental phase with trials without actually delivering the physical stimulus despite the participant's thinking that he had. The responses during the no-stimulus trials, which he called illusions or hallucinations, were assumed to be driven by inference:

The fact that the experimenter performed apparently the same manipulations that in the preparatory trials had produced a distinct sensation, formed the definite suggestion that, since the conditions were in toto repeated, the resultant sensation would recur in the same time and manner as before. By force of a firm expectant attention, caused by this inference, the image of the sensation realizes itself in a sensation projected into the peripheral organs. And in the positive instances, the observer felt it just as he expected to feel it, although there was no physical stimulus. (Seashore 1895, p. 32)

Almost a century later, the neurophysiologist Jerzi Konorski (1967) suggested that such illusory experiences could be prompted by Pavlovian conditioning, and this could also be the case with pain. 
In his account of learning, conditioning leads to the elicitation of a vivid image of the US as the CR. In some situations, that image may be mistaken as the US, and it may induce a hallucination of the US. The idea is plausible. The role of Pavlovian conditioning in the generation of respiratory complaints has been demonstrated. In a study by Van den Bergh et al. (2002), participants who inhaled an odor (CS) along with $\mathrm{CO}_{2}$-enriched air (US) - which leads to bodily symptoms such as general arousal, tingling, and respiratory and cardiac/warmth complaints—subsequently reported very similar bodily symptoms when only inhaling the neutral odor.

Some older experiments support the idea of conditioned pain (Leuba \& Dunlap 1951), and its possibility has been adopted in several books and by many clinicians (Madden \& Moseley 2016). Surprisingly, there are very few empirical studies on this topic. In a recent meta-analysis, only three experimental studies of varying methodological quality were identified, and the results suggest that it is unknown whether conditioned pain really exists. In their imprecision hypothesis of chronic pain, Moseley \& Vlaeyen (2015) reinvigorated the hypothesis that pain can be conditioned, and they suggested that chronic widespread pain, common back pain, and fibromyalgia may be forms of generalized Pavlovian conditioned pain. A more recent study using a simultaneous conditioning paradigm with tactile stimuli on the backs of healthy subjects as CSs provided initial evidence that pain thresholds can be modulated through Pavlovian conditioning (Madden et al. 2016), and this finding was successfully replicated (Traxler et al. 2019). So far, the existing literature seems to suggest that Pavlovian conditioning can modulate and amplify pain, but no conclusions can be drawn about whether classical conditioning can elicit pain itself, as suggested by Seashore (1895), Konorski (1967), and others. Yet, the answer to the question of whether pain can be conditioned, and under what conditions, may have far-reaching theoretical and clinical implications.

\section{Controlling Harm: Operant Conditioning}

Not only classical but also operant conditioning can affect pain-related behavior (Gatzounis et al. 2012). In the early 1960s, the American psychologist Wilbert Fordyce (1976) was one of the first to suggest that the development of chronic pain was the result of contingencies of reinforcement controlling observable "pain behaviors" (e.g., crying, limping, moaning, using medications), thereby maintaining the pain problem beyond the expected healing. Inspired by Skinner and Thorndike, Fordyce considered the effects of behavior as causes of future action (Thorndike 1911) and identified at least three pathways through which operant conditioning could maintain disabling pain behaviors: direct positive reinforcement (e.g., social attention), negative reinforcement (escape/avoidance from noxious stimulation), and insufficient positive reinforcement for "well behavior" (e.g., lack of praise for leisure activity, working). The idea is that after normal healing of an injury, the drivers of pain-related behaviors can shift from internal to external contingencies, depending on the value of the reinforcers following pain behavior versus the value of those following healthy behaviors. Reinforcers can act on innate defensive and recuperative behaviors mentioned above but also on new types of voluntary behavior the individual engages in to reduce suffering (e.g., consulting doctors, taking pain medication).

Most experimental studies have focused on the first pathway and have investigated whether self-report of pain is affected by positive reinforcement (Adamczyk et al. 2019). The results of the first preliminary studies that manipulated positive reinforcement were promising (Block 1981, Cairns \& Pasino 1977). In two subsequent studies, Linton \& Götestam (1985) asked healthy volunteers to rate a series of painful stimuli created by inflating a blood pressure cuff on the arm. Then they positively reinforced any subsequent increase in pain report using verbal praise (e.g., "You are doing well") in one group. In the other group, the experimenter remained neutral. The first study showed that despite repeated pain stimuli with the same intensity, pain reports increased 
in the reinforced group only. The second study was set up to mimic the clinical observation that patients display pain behaviors in the absence of a demonstrable physical anomaly. Therefore, this experiment used painful ischemic stimuli of gradually decreasing intensity. The reinforced group responded differently than the control group, as expected. Despite repeated pain stimuli with decreasing intensity, pain reports remained the same in the reinforced group, whereas the pain ratings followed the decreasing pattern of the physical stimuli in the control group. Although some replications failed (Lousberg et al. 1992), other studies were successful in establishing operant learning of pain behavior, even when contingency awareness was taken into account (Jolliffe \& Nicholas 2004). Another study elegantly demonstrated that not just pain report but also more automatically expressed facial pain expressions could fall under the control of operant conditioning without the participants being aware of the contingencies (Kunz et al. 2011). Kunz and colleagues' results also showed that the conditioned decline in facial pain displays during acquisition paralleled reductions in pain.

Few studies have tested the predictions of the operant conditioning paradigm in patients with chronic pain. An elegant study investigated differences in operant conditioning of pain responses between patients with chronic low back pain and matched controls (Flor et al. 2002). Patients displayed slower extinction of both the verbal and cortical responses (as measured by electroencephalogram) to pain despite similar learning rates in both patients and controls. In addition, the patient group displayed prolonged elevated muscle tone levels (as measured by electromyography). The results suggest that patients with chronic pain may be more sensitive to operant conditioning of pain than healthy controls, which may contribute to the maintenance of the chronic pain problem. This idea is largely unexplored and merits further investigation.

More recent studies have expanded operant conditioning formulations of patient-spouse interactions with interpersonal processes of intimacy, taking emotional content and validation of spouse responses into consideration. For example, current studies have not differentiated between different kinds of reinforcers provided by family members or coworkers, nor have they made a distinction between instrumental and emotional support or indicated whether these meet the needs of the individual in pain at a certain time (Cano \& Williams 2010).

\section{Preventing Harm: Avoidance Behavior}

Avoidance behavior takes a central position in FA models of chronic pain, and it is a potent way to prevent the occurrence of bodily harm. Fordyce et al. (1982) and Philips (1987) were among the first to provide illustrations of how various pain-related behaviors function as avoidance behaviors. Patients may limit activity, display guarding or protective behaviors, or take analgesics in anticipation of nociceptive stimuli. Most often, the assumption is that avoidance may be adaptive in the short term but that its excessive or unnecessary deployment can have detrimental consequences (van Vliet et al. 2018). At least three forms need to be distinguished. There is reflexive and almost automatic avoidance behavior as part of the Pavlovian defensive system, a more reflective instrumental avoidance behavior, and habitual avoidance due to repeated training that is not influenced by the avoidance behavior's consequences (LeDoux et al. 2017, Pittig et al. 2018).

There is little research in reflexive and habitual avoidance responses in pain research, and the topography of avoidance behavior depends on the paradigm used. For example, increased latencies have been observed in a VJP, during which CS+ movements are initiated more slowly than CS- movements (Meulders et al. 2011). In another study, which used a robotic arm, participants were requested to make circular movements in a clockwise (CS+, followed by a painful US) or counterclockwise (CS-) direction. $\mathrm{CS}+$ movements were performed faster, more forcefully, and more accurately than the safe movements. Of interest is that these differences diminish during 
a subsequent extinction phase (Karos et al. 2017). It seems that this reflexive avoidance behavior is characterized by initial slowing, followed by acceleration away from the potential source of threat. Whether this behavior is really reflexive rather than strategic needs to be ruled out in further research.

The second form of avoidance behavior is more reflective and is influenced by its consequences, such as the reduction of an aversive outcome and the importance of the associated costs, but experimental studies have been scarce. Once acquired, avoidance behavior is notoriously persistent, and this fact challenges the classic operant learning theory. When the aversive outcome is successfully avoided, reinforcement is no longer experienced, and rapid extinction should follow. A learning theory that may account for the persistence of avoidance behavior is the integrated expectancybased model, which relies on the assumption that both Pavlovian and instrumental learning imply higher-order reason-based processes (Lovibond et al. 2008). The expectancy that performing a particular response leads to the absence of the US will be the driver of that response. A particular strength of the integrated expectancy model is that it can account for the observation that avoidance can be acquired indirectly by pathways other than direct experience, such as verbal instruction and mere observation.

Insight into the role of verbal language in human behavior is one of the major innovations in learning and conditioning and is discussed in relational frame theory (RFT). Human language transforms learning by allowing inference of relations between stimuli/events that were never directly experienced (Törneke 2010). For example, if we teach a dog to react to the word food by saying that word every time we present a meal, the dog will behave in response to the word food as if the actual food were on its way. However, the dog will fail to infer the reverse relation-namely, that the actual food is equivalent to the word food (Hayes 1989). Humans have no problems with such inferences [see also the generalization study by Bennett et al. (2015) mentioned earlier] —and RFT states that the ability to form equivalent relations between stimuli is necessary to understand behavior in response to language. For instance, the instruction "You will injure your back if you lift a heavy crate" can only have an effect if there are equivalence relations between the word lift and actually lifting a crate and between the word crate and an actual crate. Furthermore, a notion of causality is implied in the instructions ("if...then"). Verbal rules provide information that otherwise might only have been learned over time by trial and error, and they can prevent catastrophic outcomes (e.g., "Do not cross the street when the traffic light is red"). Rules allow one to behave without having to directly experience the contingencies. Nevertheless, rules can have negative effects when they are erroneous (e.g., "If you are not careful with your back, you will end up in a wheelchair"). Following rules may also make individuals less sensitive to actual changes in contexts or contingencies, a phenomenon called the "rule-based insensitivity effect" (Kissi et al. 2018). In Kissi and colleagues' study, participants received either initially accurate instructions to avoid pain or no such instructions. Midway through the task, the contingencies changed. Participants either could not avoid pain anymore (they lost control over pain) or had to apply a novel strategy to avoid pain. The results indicate that compared with the no-instruction group, participants who received the verbal instructions about how to avoid pain were more inclined to stick to their initial pain-avoidance strategy when they lost control over the painful stimulus.

\section{Pain in Context}

Learning to predict and control harmful or noxious events does not occur in a vacuum but, rather, in environments with many demands to potentially act upon. Humans juggle between multiple and often-competing goals and needs. In search of the fundamental characteristics of learning, researchers have reduced the complex reality to its bare essentials. This approach has advanced 
the science of conditioning and learning but also has limited its ecological validity. We argue that considering both internal (e.g., touch, hunger, thirst, fatigue) as well as external (e.g., visual objects, auditory stimuli, presence of others) contextual elements will further pain science and improve our understanding of pain-related decision making and avoidance behavior in the natural environment of individuals with pain. Here, we consider the reciprocal influence among pain and nonpain goals and how Pavlovian cues interact with instrumental responses.

Competing goals. Daily contexts often contain multiple goals, and some of these may compete with the goal to preserve or restore the integrity of the body (Crombez et al. 2012). Chronic pain can be highly threatening, and it often results in a conflict between keeping pain at a manageable level and engaging in daily activities (Hardy et al. 2011). The motivation-decision model of pain assumes descending bidirectional pain-modulatory (opioid and dopaminergic) circuits that can enhance or diminish pain based on a weighing of rewards and punishments (Fields 2006, Wiech \& Tracey 2013). A typical situation is one in which painful activities (joining a sports game) serve a valued goal (spending time with children). Would individuals be willing to endure such activities more than they would if the activities did not serve such a goal? Claes et al. (2014) addressed this question using the VJP. In the experimental condition, one joystick movement (CS+) was followed by both a painful US (electrocutaneous stimulus) and a rewarding US (lottery ticket) on $50 \%$ of the trials, whereas the other movement was not paired with any other stimulus (CS-). In the control condition, the CS+ movement was followed by the painful US only. The results confirmed the hypothesis that the CRs were modulated by the presence of the reward, which served a competing nonpain goal, despite equal levels of conditioned pain-related fear. Compared with participants in the comparison group, those in the experimental group not only initiated a $\mathrm{CS}+$ movement as quickly as the CS- movement but also performed more painful movements during a subsequent phase in which they could freely choose between the painful or the nonpainful movement. This study provides experimental evidence that competing nonpain goals may have an impact on behavioral decision making and avoidance behavior when enduring pain. These findings also corroborate other research showing that competing nonpain goals, goal conflicts, and individual differences in goal flexibility may inhibit or overrule pain-avoidance goals (Schrooten et al. 2014, Van Damme et al. 2012).

Pavlovian and instrumental transfer. The presence of Pavlovian cues can also modulate the vigor and strength by which instrumental behavior is emitted (Rescorla \& Solomon 1967). Pavlovian cues predicting outcomes similar to the instrumental responses can increase the strength of instrumental responses, whereas dissimilar or opponent outcomes may weaken them. We recently designed an experiment containing an instrumental learning phase using the VJP with certain joystick movements followed by pain and another movement followed by reward, a Pavlovian learning phase with visual cues predicting pain or reward, and a subsequent transfer phase in which Pavlovian cues were integrated into the instrumental task (Claes et al. 2016). When participants were asked about their fear and eagerness to perform the movements before actually performing them, the presence of a cue predicting a painful outcome increased fear of the painful movement, whereas fear of the same movement was attenuated in the presence of a cue predicting a rewarding outcome. Eagerness ratings showed almost the opposite pattern: Eagerness to perform the reward movement was reduced in the presence of the cue predicting painful US. The participants' decision-making behavior was in line with these ratings. Participants were almost always willing to perform the reward movement, except in the presence of a pain cue. Similarly, the participants were overall not willing to perform a painful movement unless it was accompanied by a reward cue. These findings are in line with the idea that the sensitivity to benefits is attenuated 
as costs become increasingly aversive, and vice versa (Talmi et al. 2009). In the final transfer phase, when the participants were given the choice to actually perform one of the two movements (each of which was accompanied by one of the cues), they mostly performed the rewarded movement. When incongruent cues were presented (reward cue + the painful movement; pain cue + the reward movement), oscillatory behavior was observed. Participants switched between performing the painful and reward movements more often-a behavior that resembled the sawtooth activity pattern often seen in individuals suffering chronic pain (Nielson et al. 2013, Schrooten et al. 2014).

\section{BEHAVIORAL TREATMENT OF CHRONIC PAIN}

What are the implications of the behavioral conceptualization and its current findings as outlined above for the treatment of persistent pain? The translation from experimental research in the lab to interventions in the clinic is underestimated (Woolf 2008). Despite this challenge, a panoply of psychological treatments for individuals with chronic pain has emerged since the pioneering work of Wilbert Fordyce (Fordyce et al. 1968). These treatments include cognitive behavioral therapy (CBT), biofeedback training, contingency management, acceptance and commitment therapy, mindfulness-based stress reduction, and the application of advanced technologies (Turk \& Gatchel 2018). It is beyond the scope of this contribution to review them all. Although all of these treatments undoubtedly may have merits for certain individuals, the general picture is that psychological treatments for chronic pain show small to moderate effect sizes. Despite the progress made in recent years, our knowledge is still limited, and creating the right treatment for a particular individual with a particular problem remains a huge challenge that probably requires a paradigm shift (Morley et al. 2013). Here, we focus on recent developments in CBT from an affective-motivational perspective that share the aim of facilitating or restoring the pursuit of individual valued life goals (Karoly \& Crombez 2018, Schrooten et al. 2012).

\section{Risk Identification}

Keeping in mind that a relatively small percentage of individuals with chronic pain are responsible for the bulk of the societal costs, the early identification of patients at risk of becoming disabled might lead to more effective interventions (Nicholas et al. 2011). Screening tools have been developed to help clinicians assess the risk of chronic pain and its related disability in patients seeking care for acute pain. Most of this work has been done for back and neck pain so far and includes questions about duration of pain, emotional distress, FA beliefs, self-perceived functioning, and expected return to future goals including work (Veirman et al. 2019). One such tool is the Örebro Musculoskeletal Pain Screening Questionnaire (Linton et al. 2011), which has been clinically validated and found accurate in predicting work disability and pain outcomes in individuals with musculoskeletal pain. The screening tool might also be useful in isolating the most potent risk factors for disability, thus enabling development of a customized treatment focused on these idiosyncratic problems (Linton et al. 2018). For individuals already experiencing chronic pain and disability, a systematic analysis of their behaviors and their controlling antecedent and consequent stimulus conditions is required (Sanders 2018). Such a functional analysis is obtained through a combination of direct observation, self-report measures, and self-monitoring by patients using diaries and activity monitors.

\section{Clarification-Oriented Interventions}

Once the initial assessment has been completed, the next step consists of engaging the person in a behavioral treatment that is aimed at helping them tip the balance from dysfunctional avoidance 
behavior toward non-pain-goal-directed approach behavior. To help them disengage from avoidance behavior, unambiguously providing new information that pain is an experience that can be self-managed — rather than a serious health condition that needs careful protection-can be helpful. This implies more than just reassurance (Linton et al. 2008b) and includes interactively illustrating the paradox of avoidance by using the person's own words. The information acknowledges that avoidance is a normal form of defense in an abnormal situation of persistent pain but that after a while, this response loses its adaptiveness and becomes counterproductive. In addition, the pain is explained as not always being a sign of injury inevitably leading to disability. This new understanding should pave the way for a behavior change away from pain avoidance.

The next question relates to the orientation toward approach behavior to restore one's disrupted life. The identification of the various personal goals and intergoal relations is crucial. The aim is to reevaluate major life goals and to address possible goal conflicts. In the process of goal identification and reevaluation, competition and conflicts among these goals may arise. Conflicts are situations in which the pursuit of one activity or goal competes with the attainment of another, equally valued goal, and which create at least a temporary stalemate characterized by indecisiveness and hesitancy before the person decides which activity to pursue. The personal project analysis and the day reconstruction method, in which the patient reconstructs the previous day in keywords, may be useful tools in this process (Claes et al. 2018, Crombez et al. 2016).

An interesting intervention that can be offered to improve goal attainment is mental contrasting in combination with problem solving and the formation of implementation intentions. Contrasting the desired future (e.g., playing with my children) with the present (e.g., lying in bed most of the time) has been shown to be effective in identifying potential obstacles to the realization of the desired goals. Once these obstacles are identified, problem-solving techniques may help in finding ways to overcome them (Eccleston \& Crombez 2007, van den Hout et al. 2003). Implementation intentions create an association between a goal-directed response $Y$ and occasion $X$ through predetermined "if $X$, then $Y$ " propositions [e.g., to resume physical activity: "If I finish watching the evening news $(X)$, then I will go for a 20 -minute walk $(Y)$ "]. This "if-then" connection improves the accessibility of the critical cue in memory, and when the cue is detected, the automatic activation of desired behavior is facilitated (Oettingen et al. 2001). A brief intervention including these goal-pursuit strategies in combination with a problem-solving approach to help patients appeared to be promising in increasing physical capacity (Christiansen et al. 2010).

\section{Exposure-Based Treatments}

Intentions do not always lead to action, especially in individuals reporting increased levels of pain-related fear. Therefore, the third and probably most essential step consists of actual exposure to the situations the patient has identified as dangerous or threatening. Actual initiation of goal-directed behavior depends not only on the goals' desirability and perceived realizability but also on the distractions and obstacles that may disrupt goal striving. A major distraction is the biological function of pain itself: the urge to avoid potential harm. Individuals suffering persistent pain often find themselves in a conflict situation between avoiding activity to prevent further harm versus approaching valued life activities. This conflict is largely based on uncertainty and on the expectation that resuming activity will increase pain and body harm. One way to resolve such conflict is to explore novel actions that in turn can create prediction errors and opportunities to discover that the anticipated harm signaled by pain is actually overestimated. One tested and 
viable treatment that was developed specifically to provide these prediction errors is exposure with response prevention. Exposure is the clinical analog of a Pavlovian extinction procedure, where the pain US (or its memory representation) ceases to follow the CS. In that case, the latter loses its predictive value, and consequently the CR extinguishes. Exposure with response prevention has a long tradition in the treatment of anxiety disorders, but it also has been applied successfully in patients with chronic musculoskeletal pain (Vlaeyen et al. 2012). In this treatment, patients perform an activity to challenge the validity of their catastrophic expectancies. Also, these expectancies take the form of "if $P$, then $Q$ " propositions, which are subsequently tested during a behavioral experiment. For example, a young mother with chronic back pain may expect that lifting her 2-year-old from a crib will inevitably cause her excruciating pain, which signals potential nerve damage: "If I lift my child $(P)$, then I will damage spinal nerves $\left(Q_{1}\right)$ and I may become paralyzed $\left(Q_{2}\right)$." A behavioral experiment is designed to create the opportunity to falsify the prediction. After the therapist models the activity, the experiment is carried out and evaluated. In contrast to physical activity programs, the exposure is developed to critically challenge idiosyncratic beliefs and expectations and to encourage explorative behaviors, which can be followed by selecting and retaining the most appropriate one. Expanding the behavioral repertoire enables the restoration of function and perhaps the discovery of novel ways to enrich the person's life.

Outcome studies have shown that such exposure treatments are especially effective in reducing pain-related fear and the perceived harmfulness of physical activity in individuals with chronic pain disability and fear of pain (den Hollander et al. 2016, Leeuw et al. 2008, Linton et al. 2008a, Woods \& Asmundson 2008). Exposure-based treatments are cost-effective as well; they not only reduce pain-related fear and disability but also increase quality-adjusted life years and decrease costs compared with traditional pain treatments (den Hollander et al. 2018, Goossens et al. 2015). Smaller trials with single-case experimental designs (SCEDs) showed reduced pain reports and successful resumption of personal goals (de Jong et al. 2005, 2012). Of interest are that the outcomes are independent of the number of sessions and that exposure treatment outperforms more traditional CBT in terms of reducing movement-related disability and increasing psychological flexibility (Glombiewski et al. 2018). One concern regarding Glombiewski and colleagues' study, however, is that significantly more participants in exposure dropped out compared with those in CBT. The main reason is that they were less convinced about the benefits of exposure or wished to avoid exposure sessions. This result suggests that there is room for improvement. Although empirical tests still are needed, there are a number of possibilities for strengthening the effects of exposure from a motivational perspective. One is to include goal-pursuit strategies to increase engagement in the nonpain goals (Christiansen et al. 2010); another is to more systematically address the negative emotions often reported by individuals with chronic pain (Boersma et al. 2019).

In addition to these add-ons, there are other possibilities to optimize exposure treatment by strengthening inhibitory learning. Studies have demonstrated that a competition occurs between the original threatening (excitatory) meaning of the stimuli (CS-harm) and a new (inhibitory) meaning (CS-no harm). In other words, during successful exposure, exceptions to the rule are learned rather than a fundamental change of that rule (Bouton 1993). Ways to strengthen the inhibitory meaning of the CSs have been suggested and include the removal of safety signals, the use of multiple contexts, and linguistic processing/affect labeling (Craske et al. 2014).

Competent delivery of exposure in vivo is challenging for both the patient and the therapist. A basic dilemma in exposure therapy, as mentioned above, is discovering what the feared CS is and then being able to present it without the presence of the injury/pain (US) (Morley \& Eccleston 2004). Some individuals have the ability to create vivid images, and they may be asked to imagine performing the "harmful" physical activities they tend to avoid. For example, one could consider 
imagined exposure or exposure using virtual reality and gaming technologies instead of in vivo exposure (Trost et al. 2015). In other individuals, the stimuli that trigger the fear response may be the pain itself or proprioceptive stimuli arising from movement or increased arousal (De Peuter et al. 2011). Earlier studies that examined interoceptive exposure (e.g., in irritable bowel syndrome) by asking chronic pain patients to practice focusing on the persistent pain showed promising results (Craske et al. 2011, Flink et al. 2009).

\section{FUTURE DIRECTIONS}

\section{From Pain Perception to Pain Drive}

Although research on the role of pain-related fear has accumulated in the last two decades, the focus has been primarily on verbal and psychophysiological indices of fear, at the cost of behavioral measurement of avoidance behavior. Novel measures of avoidance behavior have been developed, including robot arm methodology, but this development lags behind other measures. Given the assumption that pain has more in common with motivational drives such as hunger and thirst than with a perceptional sensation such as vision and hearing, there are reasons to propose that we should examine pain and pain-related fear intensity beyond their verbal expression. Early theorists such as Konorski (1967) and Rescorla \& Solomon (1967) proposed that motor behavior is perhaps a more sensitive and valid index of conditioned drive. Therefore, it might be worthwhile to develop behavioral measures that can supplement the existing self-report ones so that drive strength and vigor can be assessed. One possibility would be a human version of the Sidman avoidance paradigm (Lewis et al.2013), during which a noxious stimulus can be postponed by an instrumental response. The vigor with which the instrumental response is emitted is considered an index of the strength of the drive. Such a measure still needs to be conceived in the context of pain.

\section{Exploitation-Exploration Trade-Off}

Exposure-based treatments create opportunities to disconfirm harm expectancies and reduce avoidance behavior. An important prerequisite for such expectancy violations is increasing behavioral variability and the emittance of explorative behavior. An interesting approach to better understand avoidance behavior in daily contexts, which may also improve the psychological treatment of chronic pain, is the analysis of the exploitation-exploration trade-off in chronic pain (Cohen et al. 2007). The explore/exploit dilemma represents a choice between two behavioral options in a dynamic and often-uncertain environment. Exploitation is maintaining the current status and choosing behavior on the basis of existing knowledge with the risk of missing out on opportunities for improvement. Exploration is gathering novel information with the opportunity to improve the current situation but with the risk of worsening it. We suggest that individuals in pain often show an exploitation response by choosing the action leading to the least pain (pain avoidance) instead of exploring various ways to reach valued activities. Exclusive exploitation of pain-avoidance behavior is particularly detrimental because it does not allow disconfirmation unless exploratory behavior takes place. Finding an optimal strategy to deal with risky situations, such as being in pain, might critically depend on balancing the exploitation of current information and the collection of novel information through explorative behavior (Daw et al. 2006). In nonhuman animals, findings on the exploitation-exploration trade-off during foraging show that organisms display an action pattern that is characterized by behavioral cycles with regular switching between exploratory and exploitative behavioral modes (Kembro et al. 2019). We consider this a promising new research area in the field of pain that might shed a new light on extinction of pain-avoidance 
behavior as well as on the so-called "pacing" techniques often recommended in pain management (Nielson et al. 2013).

\section{Toward a Personalized Pain Management Approach}

Randomized controlled trials (RCTs) of psychological treatments for chronic pain have been the focus of several meta-analyses. While there is good evidence that psychological treatments are effective, the magnitude of the effect is relatively small: Typical meta-analytic effect sizes are in the range of around 0.2 (Cohen's $d$ ) for the difference between active treatment and waitlist control or treatment as usual. Furthermore, there is little evidence that the magnitude of current treatment effects is improving. A recent review argued that "as more trials of psychological treatments are published, clarity becomes more, not less, elusive" (Morley et al. 2013, p. 1930). These authors argued for a paradigm shift that would develop precise testable models linking specific treatment procedures to specific psychological changes with detailed experimental work. This aim is not likely to be achieved with further RCTs, and novel study designs, such as replicated SCEDs, are indicated as viable strategies to improve treatment effectiveness. In addition, they hold a key to bridging the well-known scientist-practitioner gap and moving the field toward more personalized treatments. SCEDs accommodate the large interindividual variability and heterogeneity that are typical for individuals with chronic pain, and the data provide rich information about the sequence of changes during treatment. For example, during an exposure treatment in a patient with complex regional pain syndrome type I reporting increased pain-related fear, fear of movement was the variable that responded relatively fast to the treatment, followed by the achievement of individual life goals and, finally, lower reported pain intensity, albeit at a slower pace (de Jong et al. 2005). These data are remarkable because they suggest that pain reduction is not a prerequisite per se for the reduction of disability — an assumption that is held by many health care providers and patients alike. Finally, open-source statistical software for SCED design, randomization tests, effect size calculation, and meta-analysis is available (e.g., https://ppw.kuleuven.be/mesrg/software-andapps/shiny-scda) (Onghena et al. 2018).

\section{CONCLUSION}

The main underlying theme in this review is that pain is not only a sensory and emotional experience but, rather, part of a motivational system that alarms, directs, and energizes behavior to prevent or minimize bodily harm. From this perspective, pain is a strong driver of learning, as can be observed in behavior changes after repeated pain stimuli or in those that occur when relations between pain and concurrent events are detected. Conditioned behaviors that are initially adaptive can turn into less flexible patterns, which may then perpetuate pain and pain-related disability. We have highlighted the FA model because it integrates these learning mechanisms into a heuristic that helps deepen our understanding of how chronic pain evolves from a common pain episode to chronic, disabling pain. Clinically, this modern learning approach incorporating behavioral and motivational aspects has contributed to the development of cost-effective, exposure-based treatments, but considerable challenges remain to harvest the full benefit of the knowledge gained so far. Future efforts should focus on developing more specific assessment procedures that could direct clinicians to the best treatment options and optimize tailoring. Our hope is that the ideas expressed here will inspire our research and clinical colleagues alike and encourage continued research on the role of behavior in the transition from common acute pain to persistent disabling pain as well as research on how to reverse the disabling effects of this pain and improve quality of life in these individuals. 


\section{SUMMARY POINTS}

1. Chronic pain is highly prevalent and one of the greatest contributors of years lived with disability.

2. The international definition of pain recognizes the loose connection between pain and injury and states that pain is an unpleasant sensory and emotional experience with or without tissue damage.

3. Pain is part of a motivational system that alarms, directs, and energizes behavior to minimize threats to the organism.

4. The fear-avoidance model of chronic pain has improved our understanding of the transition from a common pain episode to burdensome, persistent pain, and a large body of evidence is in line with its assumptions.

5. Learning enables the organism to respond to the relevance of noxious stimuli (either through habituation or sensitization), to predict harmful events (Pavlovian conditioning), and to prevent harmful events through avoidance behavior (operant conditioning).

6. There is strong evidence that pain-related fear can be classically conditioned, but the question of whether pain itself as a response can be conditioned is still unanswered.

7. Individuals with disabling chronic pain seem to favor a "better safe than sorry" strategy. False alarms seem to be accepted to avoid missing a true alarm.

8. Responding to noxious events takes place in the context of competing nonpain goals and needs, which may inhibit pain and pain avoidance.

9. Exposure-based treatments can significantly reduce pain-related fear and the interference of pain in daily life. Some studies reveal a significant reduction in the report of pain intensity after pain-related fear has diminished.

\section{DISCLOSURE STATEMENT}

The authors are not aware of any affiliations, memberships, funding, or financial holdings that might be perceived as affecting the objectivity of this review.

\section{ACKNOWLEDGMENTS}

J.W.S.V. is supported by the Asthenes research program "From Acute Aversive Sensations to Chronic Bodily Symptoms," a long-term structural Methusalem funding (METH/15/011) by the Flemish government, Belgium.

\section{LITERATURE CITED}

Adamczyk WM, Buglewicz E, Szikszay TM, Luedtke K, Babel P. 2019. Reward for pain: hyperalgesia and allodynia induced by operant conditioning: systematic review and meta-analysis. F. Pain 20:861-75

Auvray M, Myin E, Spence C. 2010. The sensory-discriminative and affective-motivational aspects of pain. Neurosci. Biobehav. Rev. 34:214-23

Bennett MP, Meulders A, Baeyens F, Vlaeyen JW. 2015. Words putting pain in motion: the generalization of pain-related fear within an artificial stimulus category. Front. Psychol. 6:520 
RCT describing a goal-pursuit intervention embedded in a physical exercise program for individuals with chronic low back pain.

Empirically shows that Pavlovian cues predicting pain or reward can modulate decision making and instrumental behavior.
Benson S, Kattoor J, Kullmann JS, Hofmann S, Engler H, et al. 2014. Towards understanding sex differences in visceral pain: enhanced reactivation of classically-conditioned fear in healthy women. Neurobiol. Learn. Mem. 109:113-21

Biggs EE, Meulders A, Kaas AL, Goebel R, Vlaeyen JWS. 2017. The acquisition and extinction of fear of painful touch: a novel tactile fear conditioning paradigm. F. Pain 18:1505-16

Block AR. 1981. Investigation of the response of the spouse to chronic pain behavior. Psychosom. Med. 43:41522

Boersma K, Sodermark M, Hesser H, Flink IK, Gerdle B, Linton SJ. 2019. Efficacy of a transdiagnostic emotion-focused exposure treatment for chronic pain patients with comorbid anxiety and depression: a randomized controlled trial. Pain 160:1708-18

Bol Y, Duits AA, Lousberg R, Hupperts RM, Lacroix MH, et al. 2010. Fatigue and physical disability in patients with multiple sclerosis: a structural equation modeling approach. 7. Behav. Med. 33:355-63

Bouton ME. 1993. Context, time, and memory retrieval in the interference paradigms of Pavlovian learning. Psychol. Bull. 114:80-99

Brinjikji W, Luetmer PH, Comstock B, Bresnahan BW, Chen LE, et al. 2015. Systematic literature review of imaging features of spinal degeneration in asymptomatic populations. A7NR Am. 7. Neuroradiol. 36:81116

Brunetti ND, Guerra A, Ieva R, Correale M, Santoro F, et al. 2017. Scared for the scar: fearsome impact of acute cardiovascular disease on perceived kinesiophobia (fear of movement). Clin. Cardiol. 40:480-84

Buchbinder R, Blyth FM, March LM, Brooks P, Woolf AD, Hoy DG. 2013. Placing the global burden of low back pain in context. Best Pract. Res. Clin. Rheumatol. 27:575-89

Cairns D, Pasino JA. 1977. Comparison of verbal reinforcement and feedback in the operant treatment of disability due to chronic low back pain. Behav. Ther. 8:621-30

Cammer L. 1961. Conditioning and psychiatric theory. Am. 7. Orthopsychiatry 31:810-19

Caneiro JP, O'Sullivan P, Smith A, Ovrebekk IR, Tozer L, et al. 2019. Physiotherapists implicitly evaluate bending and lifting with a round back as dangerous. Musculoskelet Sci. Pract. 39:107-14

Cano A, Williams AC. 2010. Social interaction in pain: reinforcing pain behaviors or building intimacy? Pain 149:9-11

Ceunen E, Zaman J, Weltens N, Sarafanova E, Arijs V, et al. 2016. Learned fear of gastrointestinal sensations in healthy adults. Clin. Gastroenterol. Hepatol. 14:1552-58.e2

Christiansen S, Oettingen G, Dahme B, Klinger R. 2010. A short goal-pursuit intervention to improve physical capacity: a randomized clinical trial in chronic back pain patients. Pain 149:444-52

Claes N, Karos K, Meulders A, Crombez G, Vlaeyen JW. 2014. Competing goals attenuate avoidance behavior in the context of pain. F. Pain 15:1120-29

Claes N, Vlaeyen JWS, Crombez G. 2016. Pain in context: cues predicting a reward decrease fear of movement related pain and avoidance behavior. Behav. Res. Ther: 84:35-44

Claes N, Vlaeyen JWS, Lauwerier E, Meulders M, Crombez G. 2018. Goal conflict in chronic pain: day reconstruction method. Peerf 6:e5272

Cohen JD, McClure SM, Yu AJ. 2007. Should I stay or should I go? How the human brain manages the trade-off between exploitation and exploration. Philos. Trans. R. Soc. B 362:933-42

Cox JJ, Reimann F, Nicholas AK, Thornton G, Roberts E, et al. 2006. An SCN9A channelopathy causes congenital inability to experience pain. Nature 444:894-98

Craig AD. 2002. How do you feel? Interoception: the sense of the physiological condition of the body. Nat. Rev. Neurosci. 3:655-66

Craske MG, Treanor M, Conway CC, Zbozinek T, Vervliet B. 2014. Maximizing exposure therapy: an inhibitory learning approach. Behav. Res. Ther. 58:10-23

Craske MG, Wolitzky-Taylor KB, Labus J, Wu S, Frese M, et al. 2011. A cognitive-behavioral treatment for irritable bowel syndrome using interoceptive exposure to visceral sensations. Behav. Res. Ther. 49:413-21

Crombez G, Eccleston C, Baeyens F, Eelen P. 1998a. Attentional disruption is enhanced by the threat of pain. Behav. Res. Ther. 36:195-204

Crombez G, Eccleston C, Baeyens F, Eelen P. 1998b. When somatic information threatens, catastrophic thinking enhances attentional interference. Pain 75:187-98 
Crombez G, Eccleston C, Van Damme S, Vlaeyen JW, Karoly P. 2012. Fear-avoidance model of chronic pain: the next generation. Clin. 7. Pain 28:475-83

Crombez G, Eccleston C, Vlaeyen JW, Vansteenwegen D, Lysens R, Eelen P. 2002. Exposure to physical movements in low back pain patients: restricted effects of generalization. Health Psychol.21:573-78

Crombez G, Lauwerier E, Goubert L, Van Damme S. 2016. Goal pursuit in individuals with chronic pain: a personal project analysis. Front. Psychol. 7:966

Crombez G, Vlaeyen JW, Heuts PH, Lysens R. 1999. Pain-related fear is more disabling than pain itself: evidence on the role of pain-related fear in chronic back pain disability. Pain 80:329-39

Darwin C. 1897. The Expression of Emotions in Man and Animals. New York: Appleton and Co.

Daw ND, O’Doherty JP, Dayan P, Seymour B, Dolan RJ. 2006. Cortical substrates for exploratory decisions in humans. Nature 441:876-79

de Jong JR, Vlaeyen JW, Onghena P, Cuypers C, den Hollander M, Ruijgrok J. 2005. Reduction of painrelated fear in complex regional pain syndrome type I: the application of graded exposure in vivo. Pain 116:264-75

de Jong JR, Vlaeyen JW, van Eijsden M, Loo C, Onghena P. 2012. Reduction of pain-related fear and increased function and participation in work-related upper extremity pain (WRUEP): effects of exposure in vivo. Pain 153:2109-18

De Paepe AL, Williams ACC, Crombez G. 2019. Habituation to pain: a motivational-ethological perspective. Pain 160:1693-97

De Peuter S, Van Diest I, Vansteenwegen D, Van den Bergh O, Vlaeyen JW. 2011. Understanding fear of pain in chronic pain: interoceptive fear conditioning as a novel approach. Eur. F. Pain 15:889-94

De Ruddere L, Goubert L, Vervoort T, Prkachin KM, Crombez G. 2012. We discount the pain of others when pain has no medical explanation. F. Pain 13:1198-205

Delbaere K, Crombez G, van Haastregt JC, Vlaeyen JW. 2009. Falls and catastrophic thoughts about falls predict mobility restriction in community-dwelling older people: a structural equation modelling approach. Aging Ment. Health 13:587-92

den Hollander M, Goossens M, de Jong J, Ruijgrok J, Oosterhof J, et al. 2016. Expose or protect? A randomized controlled trial of exposure in vivo versus pain-contingent treatment as usual in patients with complex regional pain syndrome type 1. Pain 157:2318-29

den Hollander M, Heijnders N, de Jong JR, Vlaeyen JWS, Smeets R, Goossens M. 2018. Exposure in vivo versus pain-contingent physical therapy in Complex Regional Pain Syndrome Type I: a cost-effectiveness analysis. Int. 7. Technol. Assess. Health Care 34:400-9

Dunsmoor JE, Murphy GL. 2015. Categories, concepts, and conditioning: how humans generalize fear. Trends Cogn. Sci. 19:73-77

Eccleston C, Crombez G. 1999. Pain demands attention: a cognitive-affective model of the interruptive function of pain. Psychol. Bull. 125:356-66

Eccleston C, Crombez G. 2007. Worry and chronic pain: a misdirected problem solving model. Pain 132:23336

Eelen P. 2018. Classical conditioning: classical yet modern. Psychol. Belg. 58:196-211

Fields HL. 2006. A motivation-decision model of pain: the role of opioids. In Proceedings of the 11th World Congress on Pain 2006, ed. JO Dostrovsky, H Flor, E Kalso, pp. 449-59. Seattle, WA: IASP Press

Flink IK, Nicholas MK, Boersma K, Linton SJ. 2009. Reducing the threat value of chronic pain: a preliminary replicated single-case study of interoceptive exposure versus distraction in six individuals with chronic back pain. Behav. Res. Ther. 47:721-28

Flor H, Knost B, Birbaumer N. 2002. The role of operant conditioning in chronic pain: an experimental investigation. Pain 95:111-18

Flor H, Turk DC. 1989. Psychophysiology of chronic pain: do chronic pain patients exhibit symptom-specific psychophysiological responses? Psychol. Bull. 105:215-59

Fordyce WE. 1976. Behavioral Methods for Chronic Pain and Illness. St. Louis, MO: Mosby

Fordyce WE, Fowler RS, DeLateur B. 1968. An application of behavior modification technique to a problem of chronic pain. Behav. Res. Ther. 6:105-7
Narrative review proposes a shift toward a motivational approach to pain-related fear and avoidance behavior.

Novel motivationalethological perspective on pain habituation; proposes that response to noxious stimulus depends on relevance of stimulus.

\section{First RCT to}

systematically test effectiveness of exposure treatment for individuals with complex regional pain syndrome reporting increased pain-related fear.

Novel cognitiveaffective approach to pain being an important interrupter of daily tasks, depending on its novelty, threat value, predictability, and intensity.

Classic textbook on the behavioral approach to chronic pain, which was republished in 2014 (https://ebooks.iasppain.org/behavioral_ methods). 
Critical review and state-of-the art summary of the operant learning theory applied in chronic pain.

RCT comparing effectiveness of brief exposure treatment, long exposure treatment, and coping-oriented CBT for chronic low back pain.
Fordyce WE, Shelton JL, Dundore DE. 1982. The modification of avoidance learning pain behaviors. F. Behav. Med. 5:405-14

Fortenbaugh W. 1969. Aristotle: emotion and moral virtue. Arethusa 2:163-85

Gaskin DJ, Richard P. 2012. The economic costs of pain in the United States. F. Pain 13:715-24

Gatzounis R, Schrooten MG, Crombez G, Vlaeyen JW. 2012. Operant learning theory in pain and chronic pain rehabilitation. Curr. Pain Headache Rep. 16:117-26

Gheldof EL, Crombez G, Van den Bussche E, Vinck J, Van Nieuwenhuyse A, et al. 2010. Pain-related fear predicts disability, but not pain severity: a path analytic approach of the fear-avoidance model. Eur. 7 . Pain 14:870.e1-9

Gheldof EL, Vinck J, Vlaeyen JW, Hidding A, Crombez G. 2007. Development of and recovery from shortand long-term low back pain in occupational settings: a prospective cohort study. Eur. F. Pain 11:841-54

Glombiewski JA, Holzapfel S, Riecke J, Vlaeyen JWS, de Jong J, et al. 2018. Exposure and CBT for chronic back pain: an RCT on differential efficacy and optimal length of treatment. 7 . Consult. Clin. Psychol. 86:533-45

Glombiewski JA, Riecke J, Holzapfel S, Rief W, Konig S, et al. 2015. Do patients with chronic pain show autonomic arousal when confronted with feared movements? An experimental investigation of the fearavoidance model. Pain 156:547-54

Goossens ME, de Kinderen RJ, Leeuw M, de Jong JR, Ruijgrok J, et al. 2015. Is exposure in vivo cost-effective for chronic low back pain? A trial-based economic evaluation. BMC Health Serv. Res. 15:549

Goubert L, Crombez G, De Bourdeaudhuij I. 2004. Low back pain, disability and back pain myths in a community sample: prevalence and interrelationships. Eur. 7. Pain 8:385-94

Goubert L, Vlaeyen JW, Crombez G, Craig KD. 2011. Learning about pain from others: an observational learning account. F. Pain 12:167-74

Gramsch C, Kattoor J, Icenhour A, Forsting M, Schedlowski M, et al. 2014. Learning pain-related fear: neural mechanisms mediating rapid differential conditioning, extinction and reinstatement processes in human visceral pain. Neurobiol. Learn. Mem. 116C:36-45

Gray R. 2019. On the context and character of pain experience. Pac. Philos. Q. 100:47-68

Hardy JD, Wolff HG, Goodell H. 1952. Studies on pain: measurements of aching pain threshold and discrimination of differences in intensity of aching pain. F. Appl. Physiol. 5:247-55

Hardy JK, Crofford LJ, Segerstrom SC. 2011. Goal conflict, distress, and pain in women with fibromyalgia: a daily diary study. 7. Psychosom. Res. 70:534-40

Hashmi JA, Baliki MN, Huang L, Baria AT, Torbey S, et al. 2013. Shape shifting pain: chronification of back pain shifts brain representation from nociceptive to emotional circuits. Brain 136:2751-68

Hayes SC. 1989. Nonhumans have not yet shown stimulus equivalence. F. Exp. Anal. Behav. 51:385-92

Helsen K, Goubert L, Peters ML, Vlaeyen JW. 2011. Observational learning and pain-related fear: an experimental study with colored cold pressor tasks. F. Pain 12:1230-39

Henschke N, Kamper SJ, Maher CG. 2015. The epidemiology and economic consequences of pain. Mayo Clin. Proc. 90:139-47

Hollis KL. 1984. The biological function of Pavlovian conditioning: the best defense is a good offense. F. Exp. Psychol. Anim. Behav. Process 10:413-25

Houben RM, Gijsen A, Peterson J, de Jong PJ, Vlaeyen JW. 2005. Do health care providers' attitudes towards back pain predict their treatment recommendations? Differential predictive validity of implicit and explicit attitude measures. Pain 114:491-98

IASP (Int. Assoc. Study Pain). 1979. Pain terms: a list with definitions and notes on usage. Recommended by the IASP Subcommittee on Taxonomy. Pain 6:249

Icenhour A, Kattoor J, Benson S, Boekstegers A, Schlamann M, et al. 2015. Neural circuitry underlying effects of context on human pain-related fear extinction in a renewal paradigm. Hum. Brain Mapp. 36:3179-93

Icenhour A, Labrenz F, Ritter C, Theysohn N, Forsting M, et al. 2017. Learning by experience? Visceral painrelated neural and behavioral responses in a classical conditioning paradigm. Neurogastroenterol. Motil. 29(6):e13026

Jepma M, Wager TD. 2015. Conceptual conditioning: mechanisms mediating conditioning effects on pain. Psychol. Sci. 26:1728-39 
Jolliffe CD, Nicholas MK. 2004. Verbally reinforcing pain reports: an experimental test of the operant model of chronic pain. Pain 107:167-75

Jordan KP, Sim J, Croft P, Blyth F. 2019. Pain that does not interfere with daily life-a new focus for population epidemiology and public health? Pain 160:281-85

Karoly P, Crombez G. 2018. Motivational Perspectives in Chronic Pain. New York: Oxford Univ. Press

Karos K, Meulders A, Gatzounis R, Seelen HAM, Geers RPG, Vlaeyen JWS. 2017. Fear of pain changes movement: motor behaviour following the acquisition of pain-related fear. Eur. F. Pain 21:1432-42

Kembro JM, Lihoreau M, Garriga J, Raposo EP, Bartumeus F. 2019. Bumblebees learn foraging routes through exploitation-exploration cycles. F. R. Soc. Interface 16:20190103

King S, Chambers CT, Huguet A, MacNevin RC, McGrath PJ, et al. 2011. The epidemiology of chronic pain in children and adolescents revisited: a systematic review. Pain 152:2729-38

Kissi A, Hughes S, De Schryver M, De Houwer J, Crombez G. 2018. Examining the moderating impact of plys and tracks on the insensitivity effect: a preliminary investigation. Psychol. Rec. 68:431-40

Klinger R, Matter N, Kothe R, Dahme B, Hofmann UG, Krug F. 2010. Unconditioned and conditioned muscular responses in patients with chronic back pain and chronic tension-type headaches and in healthy controls. Pain 150:66-74

Konorski J. 1967. Integrative Activity of the Brain: An Interdisciplinary Approach. Chicago: Univ. Chicago Press

Kunz M, Rainville P, Lautenbacher S. 2011. Operant conditioning of facial displays of pain. Psychosom. Med. $73: 422-31$

Latremoliere A, Woolf CJ. 2009. Central sensitization: a generator of pain hypersensitivity by central neural plasticity. F. Pain 10:895-926

LeDoux JE, Moscarello J, Sears R, Campese V. 2017. The birth, death and resurrection of avoidance: a reconceptualization of a troubled paradigm. Mol. Psychiatry 22:24-36

Leeuw M, Goossens ME, van Breukelen GJ, de Jong JR, Heuts PH, et al. 2008. Exposure in vivo versus operant graded activity in chronic low back pain patients: results of a randomized controlled trial. Pain 138:192-207

Lethem J, Slade PD, Troup JD, Bentley G. 1983. Outline of a fear-avoidance model of exaggerated pain perception-I. Behav. Res. Ther. 21:401-8

Leuba C, Dunlap R. 1951. Conditioning imagery. 7. Exp. Psychol. 41:352-55

Lewis AH, Niznikiewicz MA, Delamater AR, Delgado MR. 2013. Avoidance-based human Pavlovian-toinstrumental transfer. Eur. F. Neurosi. 38:3740-48

Linton SJ, Boersma K, Jansson M, Overmeer T, Lindblom K, Vlaeyen JW. 2008a. A randomized controlled trial of exposure in vivo for patients with spinal pain reporting fear of work-related activities. Eur. F. Pain $12: 722-30$

Linton SJ, Götestam KG. 1985. Controlling pain reports through operant conditioning: a laboratory demonstration. Percept. Mot. Skills 60:427-37

Linton SJ, McCracken LM, Vlaeyen JW. 2008b. Reassurance: help or hinder in the treatment of pain. Pain 134(1-2):5-8

Linton SJ, Melin L, Götestam KG. 1984. Behavioral analysis of chronic pain and its management. Prog. Behav. Modif. 18:1-42

Linton SJ, Nicholas M, MacDonald S. 2011. Development of a short form of the Örebro Musculoskeletal Pain Screening Questionnaire. Spine 36:1891-95

Linton SJ, Nicholas M, Shaw W. 2018. Why wait to address high-risk cases of acute low back pain? A comparison of stepped, stratified, and matched care. Pain 159:2437-41

Lousberg R, Schmidt AJ, Groenman NH. 1992. The relationship between spouse solicitousness and pain behavior: searching for more experimental evidence. Pain 51:75-79

Lovibond PF, Saunders JC, Weidemann G, Mitchell CJ. 2008. Evidence for expectancy as a mediator of avoidance and anxiety in a laboratory model of human avoidance learning. Q. F. Exp. Psychol. 61:1199216

Lowen MB, Mayer E, Tillisch K, Labus J, Naliboff B, et al. 2015. Deficient habituation to repeated rectal distensions in irritable bowel syndrome patients with visceral hypersensitivity. Neurogastroenterol. Motil. 27:646-55
Comprehensive textbook presenting a cohesive account of the adaptation to chronic pain from a motivational perspective.

This paper laid the cornerstones of current fear-avoidance models of chronic pain.

Compares three forms of managing individuals with acute low back pain identified as at high risk of chronic pain. 
Describes a novel proprioceptive fear conditioning paradigm using joystick movements in an experimental setting.

Reinvigorates the idea that pain can be a conditioned response and that generalized pain is due to imprecise encoding of nociceptive information.
Madden VJ, Bellan V, Russek LN, Camfferman D, Vlaeyen JW, Moseley GL. 2016. Pain by association? Experimental modulation of human pain thresholds using classical conditioning. 7. Pain 17:1105-15

Madden VJ, Moseley GL. 2016. Do clinicians think that pain can be a classically conditioned response to a non-noxious stimulus? Man. Ther: 22:165-73

Malec J, Glasgow RE, Ely R, Kling J. 1977. Coping with pain: a self-management approach. 7SAS Cat. Sel. Doc. Psychol. 7:1601

Martinez-Calderon J, Flores-Cortes M, Morales-Asencio JM, Luque-Suarez A. 2019. Pain-related fear, pain intensity and function in individuals with chronic musculoskeletal pain: a systematic review and metaanalysis. F. Pain 20:1394-415

Mertens G, Boddez Y, Sevenster D, Engelhard IM, De Houwer J. 2018. A review on the effects of verbal instructions in human fear conditioning: empirical findings, theoretical considerations, and future directions. Biol. Psychol. 137:49-64

Meulders A, Jans A, Vlaeyen JW. 2015. Differences in pain-related fear acquisition and generalization: an experimental study comparing fibromyalgia patients and healthy controls. Pain 156(1):108-22

Meulders A, Meulders M, Stouten I, De Bie J, Vlaeyen JW. 2017. Extinction of fear generalization: a comparison between fibromyalgia patients and healthy control participants. F. Pain 18:79-95

Meulders A, Vansteenwegen D, Vlaeyen JW. 2011. The acquisition of fear of movement-related pain and associative learning: a novel pain-relevant human fear conditioning paradigm. Pain 152:246069

Meulders A, Vlaeyen JW. 2012. Reduction of fear of movement-related pain and pain-related anxiety: an associative learning approach using a voluntary movement paradigm. Pain 153:1504-13

Meulders A, Vlaeyen JW. 2013. The acquisition and generalization of cued and contextual pain-related fear: an experimental study using a voluntary movement paradigm. Pain 154:272-82

Morley JS, Eccleston C. 2004. The object of fear in pain. In Understanding and Treating Fear of Pain, ed. GJG Asmundson, JWS Vlaeyen, G Crombez, pp. 163-88. Oxford, UK: Oxford Univ. Press

Morley S, Williams A, Eccleston C. 2013. Examining the evidence about psychological treatments for chronic pain: time for a paradigm shift? Pain 154:1929-31

Moseley GL, Vlaeyen JW. 2015. Beyond nociception: the imprecision hypothesis of chronic pain. Pain 156:35-38

Mouraux A, Iannetti GD. 2018. The search for pain biomarkers in the human brain. Brain 141:3290-307

Nahin RL. 2015. Estimates of pain prevalence and severity in adults: United States, 2012. 7. Pain 16:76980

Nicholas MK, Linton SJ, Watson PJ, Main CJ. 2011. Early identification and management of psychological risk factors ("yellow flags") in patients with low back pain: a reappraisal. Phys. Ther: 91:737-53

Nielson WR, Jensen MP, Karsdorp PA, Vlaeyen JW. 2013. Activity pacing in chronic pain: concepts, evidence, and future directions. Clin. 7. Pain 29:461-68

Oettingen G, Pak H, Schnetter K. 2001. Self-regulation of goal setting: turning free fantasies about the future into binding goals. 7. Pers. Soc. Psychol. 80:736-53

Onghena P, Michiels B, Jamshidi L, Moeyaert M, Van den Noortgate W. 2018. One by one: accumulating evidence by using meta-analytical procedures for single-case experiments. Brain Impair. 19:33-58

Philips HC. 1987. Avoidance behaviour and its role in sustaining chronic pain. Behav. Res. Ther: 25:273-79

Pitcher MH, Von Korff M, Bushnell MC, Porter L. 2019. Prevalence and profile of high-impact chronic pain in the United States. 7. Pain 20:146-60

Pittig A, Treanor M, LeBeau RT, Craske MG. 2018. The role of associative fear and avoidance learning in anxiety disorders: gaps and directions for future research. Neurosci. Biobehav. Rev. 88:117-40

Rankin CH, Abrams T, Barry RJ, Bhatnagar S, Clayton DF, et al. 2009. Habituation revisited: an updated and revised description of the behavioral characteristics of habituation. Neurobiol. Learn. Mem. 92:135-38

Rescorla RA, Solomon RL. 1967. Two-process learning theory: relationships between Pavlovian conditioning and instrumental learning. Psychol. Rev. 74:151-82

Sanders SH. 2018. Operant and related conditioning with chronic pain: back to basics. In Psychological Approaches to Pain Management: A Practitioner's Handbook, ed. DC Turk, RJ Gatchel, pp. 96-114. New York: Guilford. 3rd ed. 
Schneider C, Palomba D, Flor H. 2004. Pavlovian conditioning of muscular responses in chronic pain patients: central and peripheral correlates. Pain 112:239-47

Schrooten MG, Vlaeyen JW, Morley S. 2012. Psychological interventions for chronic pain: reviewed within the context of goal pursuit. Pain Manag. 2:141-50

Schrooten MGS, Wiech K, Vlaeyen JWS. 2014. When pain meets...pain-related choice behavior and pain perception in different goal conflict situations. F. Pain 15:1166-78

Seashore CE. 1895. Measurements of illusions and hallucinations in normal life. Stud. Yale Psychol. Lab. 3:1-67

Smith BW, Tooley EM, Montague EQ, Robinson AE, Cosper CJ, Mullins PG. 2008. Habituation and sensitization to heat and cold pain in women with fibromyalgia and healthy controls. Pain 140:420-28

Sokolov EN. 1963. Higher nervous functions; the orienting reflex. Annu. Rev. Physiol. 25:545-80

Stankewitz A, May A. 2009. The phenomenon of changes in cortical excitability in migraine is not migrainespecific-a unifying thesis. Pain 145:14-17

Talmi D, Dayan P, Kiebel SJ, Frith CD, Dolan RJ. 2009. How humans integrate the prospects of pain and reward during choice. 7. Neurosci. 29:14617-26

Testa TJ. 1974. Causal relationships and the acquisition of avoidance responses. Psychol. Rev. 81:491-505

Thorndike EL. 1911. Animal Intelligence: Experimental Studies. New York: Macmillan

Törneke N. 2010. Learning RFT: An Introduction to Relational Frame Theory and Its Clinical Application. Oakland, CA: Context Press

Traxler J, Madden VJ, Moseley GL, Vlaeyen JWS. 2019. Modulating pain thresholds through classical conditioning. Peerf 7:e6486

Trost Z, France CR, Thomas JS. 2008. Exposure to movement in chronic back pain: evidence of successful generalization across a reaching task. Pain 137:26-33

Trost Z, Zielke M, Guck A, Nowlin L, Zakhidov D, et al. 2015. The promise and challenge of virtual gaming technologies for chronic pain: the case of graded exposure for low back pain. Pain Manag. 5:197-206

Turk DC, Gatchel RJ. 2018. Psychological Approaches to Pain Management: A Practitioner's Handbook. New York: Guilford. 3rd ed.

Van Damme S, Van Ryckeghem DM, Wyffels F, Van Hulle L, Crombez G. 2012. No pain no gain? Pursuing a competing goal inhibits avoidance behavior. Pain 153:800-4

Van den Bergh O, Winters W, Devriese S, Van Diest I. 2002. Learning subjective health complaints. Scand. F. Psychol. 43:147-52

van den Hout JH, Vlaeyen JW, Heuts PH, Zijlema JH, Wijnen JA. 2003. Secondary prevention of work-related disability in nonspecific low back pain: does problem-solving therapy help? A randomized clinical trial. Clin. F. Pain 19:87-96

Van der Biest L, Legrain V, Paepe AD, Crombez G. 2016. Watching what's coming near increases tactile sensitivity: an experimental investigation. Behav. Brain Res. 297:307-14

van Vliet CM, Meulders A, Vancleef LMG, Vlaeyen JWS. 2018. The opportunity to avoid pain may paradoxically increase fear. F. Pain 19:1222-30

Veirman E, Van Ryckeghem DML, De Paepe A, Kirtley OJ, Crombez G. 2019. Multidimensional screening for predicting pain problems in adults: a systematic review of screening tools and validation studies. Pain Rep. 4(5):e775

Vervoort T, Trost Z. 2017. Examining affective-motivational dynamics and behavioral implications within the interpersonal context of pain. 7. Pain 18:1174-83

Vlaeyen JW. 2015. Learning to predict and control harmful events: chronic pain and conditioning. Pain 156(Suppl. 1):S86-93

Vlaeyen JW, Kole-Snijders A, Boeren R, van Eek H. 1995. Fear of movement/(re)injury in chronic low back pain and its relation to behavioral performance. Pain 62:363-72

Vlaeyen JW, Linton SJ. 2000. Fear-avoidance and its consequences in chronic musculoskeletal pain: a state of the art. Pain 85:317-32

Vlaeyen JW, Morley S, Linton S, Boersma K, De Jong J. 2012. Pain-Related Fear: Exposure-Based Treatment for Chronic Pain. Seattle, WA: IASP Press

Vlaeyen JW, Seelen HA, Peters M, de Jong P, Aretz E, et al. 1999. Fear of movement/(re)injury and muscular reactivity in chronic low back pain patients: an experimental investigation. Pain 82:297-304
Early work providing empirical evidence supporting a cognitive-affective approach of the fear-avoidance model of pain.

Highly cited narrative early review featuring the fear-avoidance model of pain. 
Vossen CJ, Vossen HG, Joosten EA, van Os J, Lousberg R. 2015. Does habituation differ in chronic low back pain subjects compared to pain-free controls? A cross-sectional pain rating ERP study reanalyzed with the ERFIA multilevel method. Medicine 94:e865

Waddell G, Newton M, Henderson I, Somerville D, Main CJ. 1993. A Fear-Avoidance Beliefs Questionnaire (FABQ) and the role of fear-avoidance beliefs in chronic low back pain and disability. Pain 52:157-68

Wall PD. 1979. On the relation of injury to pain. The John J. Bonica lecture. Pain 6:253-64

Wideman TH, Adams H, Sullivan MJ. 2009. A prospective sequential analysis of the fear-avoidance model of pain. Pain 145:45-51

Wideman TH, Asmundson GG, Smeets RJ, Zautra AJ, Simmonds MJ, et al. 2013. Rethinking the fear avoidance model: toward a multidimensional framework of pain-related disability. Pain 154:2262-65

Wiech K, Tracey I. 2013. Pain, decisions, and actions: a motivational perspective. Front. Neurosci. 7:46

Wijenberg MLM, Stapert SZ, Verbunt JA, Ponsford JL, Van Heugten CM. 2017. Does the fear avoidance model explain persistent symptoms after traumatic brain injury? Brain Inj. 31:1597-604

Woods MP, Asmundson GJ. 2008. Evaluating the efficacy of graded in vivo exposure for the treatment of fear in patients with chronic back pain: a randomized controlled clinical trial. Pain 136:271-80

Woolf CJ. 2011. Central sensitization: implications for the diagnosis and treatment of pain. Pain 152:S2-15

Woolf SH. 2008. The meaning of translational research and why it matters. FAMA 299:211-13

Zale EL, Lange KL, Fields SA, Ditre JW. 2013. The relation between pain-related fear and disability: a metaanalysis. F. Pain 14:1019-30 


\section{h}

Annual Review of

Clinical Psychology

Volume 16, 2020

\section{Contents}

Bottom-Up and Top-Down Paradigms for Psychopathology:

A Half-Century Odyssey

Thomas M. Achenbach

Accounting for Confounding in Observational Studies

Brian M. D'Onofrio, Arvid Sjölander, Benjamin B. Lahey,

Paul Lichtenstein, and A. Sara Öberg

Personalized Models of Psychopathology

Aidan G.C. Wright and William C. Woods .

The General Factor of Psychopathology

Gregory T. Smith, Emily A. Atkinson, Heather A. Davis,

Elizabeth N. Riley, and Foshua R. Oltmanns

Interventions for Couples

Thomas N. Bradbury and Guy Bodenmann

Research on Improving Outcomes and Reducing Costs

of Psychological Interventions: Toward Delivering the Best

to the Most for the Least

Brian T. Yates

Risk and Resilience in Minority Youth Populations

Amy K. Marks, G. Alice Woolverton, and Cynthia García Coll ....

Stress and Psychiatric Disorders: The Role of Mitochondria

Teresa E. Daniels, Elizabeth M. Olsen, and Audrey R. Tyrka

Behavioral Conceptualization and Treatment of Chronic Pain

Fohan W.S. Vlaeyen and Geert Crombez

Intergenerational Transmission of Depression

Sherryl H. Goodman

Creativity and Bipolar Disorder: A Shared Genetic Vulnerability

Tiffany A. Greenwood 
Social Safety Theory: A Biologically Based Evolutionary Perspective on Life Stress, Health, and Behavior George M. Slavich

The Mentalizing Approach to Psychopathology: State of the Art and Future Directions

Patrick Luyten, Chloe Campbell, Elizabeth Allison, and Peter Fonagy

Epigenetics, Development, and Psychopathology

Kieran 7. O'Donnell and Michael 7. Meaney ....

Prevention and Management of Childhood Obesity and Its Psychological and Health Comorbidities Fustin D. Smith, Emily Fu, and Marissa A. Kobayashi

Conceptualization, History, and Future of the Paraphilias

Charles Moser and Peggy 7. Kleinplatz

Stress Allostasis in Substance Use Disorders: Promise, Progress, and Emerging Priorities in Clinical Research Gaylen E. Fronk, Sarah 7. Sant'Ana, Fesse T. Kaye, and Fohn 7. Curtin 401

Executive Function and Psychopathology: A Neurodevelopmental Perspective Philip David Zelazo

\section{Errata}

An online log of corrections to Annual Review of Clinical Psychology articles may be found at http://www.annualreviews.org/errata/clinpsy 